\title{
HUBUNGAN PERSEPSI MENGENAI PROSES BIMBINGAN KLINIK DENGAN TINGKAT KECEMASAN PADA MAHASISWA PRAKTEK KLINIK KEPERAWATAN SEMESTER III PSIK FK UNSRAT DI RS BHAYANGKARA DAN PUSKESMAS BAHU MANADO
}

\author{
Ekaristy Johannis \\ Andi Buanasari \\ Hendro Bidjuni \\ Program Studi Ilmu Keperawatan Fakultas Kedokteran \\ Universitas Sam Ratulangi Manado \\ Email: ekaristyjoh@gmail.com
}

\begin{abstract}
One of the factors that influence the occurrence of anxiety in students when clinical practices is the guidance process by the clinic advisor. Anxiety that appears to students when clinical practice can affect student intervention to patients and can be harmful for patients. The purpose of this research is to find out about the relationship between perception regarding clinical guidance process and the anxiety level of the 3Th semester of clinical nursing students of PSIK Unsrat in Bhayangkara hospital and puskesmas Bahu Manado. The method used in this study is cross-sectional study design involving 73 students in clinical practice as the respondents. Data collection was done using the NCTEI questionnaires and ZSAS. The Results of this study, out of 47 students most of them had perceptions of clinical guidance process in the poor category (64.4\%) and experienced light anxiety (57.5\%) by using the Spearman Rank test, $\rho$ value $=0,000$ is smaller than the $\alpha$ value, 0.05. In conclusion of this study there is a relationship between perceptions of clinical guidance process and anxiety levels of clinical nursing practice students.
\end{abstract}

Keywords: Anxiety, Clinical Guidance Process, Clinic Adviser

\begin{abstract}
Abstrak : Salah satu faktor yang mempengaruhi terjadinya kecemasan pada mahasiswa pada saat melaksanakan praktek klinik keprawatan yaitu proses bimbingan yang diberikan oleh pembimbing klinik. Kecemasan yang muncul pada mahasiswa saat melaksanakan praktek klinik keperawatan dapat mempengaruhi intervensi mahasiswa terhadap klien dan dapat membahayakan klien. Tujuan untuk mengetahui hubungan persepsi mengenai proses bimbingan klinik dengan tingkat kecemasan mahasiswa praktek klinik keperawatan semester III PSIK FK Unsrat di RS Bhayangkara dan Puskesmas Bahu Manado. Metode pada penelitian ini menggunakan desain penelitian cross sectional dengan melibatkan 73 mahasiswa praktek klinik sebagai responden. Pengumpulan data dilakukan menggunakan kuesioner NCTEI dan ZSAS. Hasil penelitian menunjukkan bahwa sebanyak 47 mahasiswa $(64,4 \%)$ mempersepsikan proses bimbingan klinik pada kategori kurang baik dan sebanyak 42 mahasiswwa $(57,5 \%)$ mengalami kecemasan ringan. Dari hasil statistik dengan menggunakan uji Spearman Rank didapatkan nilai $\rho$ value 0,000 lebih kecil dari nilai $\alpha$ 0,05. Kesimpulan ada hubungan antara persepsi mengenai proses bimbingan klinik dengan tingkat kecemasan mahasiswa praktek klinik keperawatan.

Kata Kunci : Kecemasan, Proses Bimbingan Klinik, Pembimbing Klinik
\end{abstract}




\section{PENDAHULUAN}

Kesehatan mental merupakan hal yang sangat penting bagi manusia sama halnya seperti kesehatan fisik pada umumnya, dengan sehatnya mental seseorang maka aspek kehidupan yang lain dalam dirinya akan bekerja secara lebih maksimal dan kondisi mental yang sehat tidak dapat terlepas dari kondisi kesehatan fisik yang baik (Nelwati, dkk. 2012). Kecemasan merupakan salah satu gangguan mental dan lebih dari 260 juta orang hidup dengan gangguan kecemasan di Dunia (World Health Organization, 2016). Prevalensi gangguan mental sering mulai terjadi pada usia muda dari pada populasi usia lain (WHO, 2016). Dalam penelitian di Universitas Garmian Iraq menunjukkan bahwa prevalensi gangguan kecemasan pada mahasiswa lebih dari $80 \%$ (Seidi, 2017). Di Indonesia prevalensi gangguan mental emosional yang ditunjukkan dengan gejala kecemasan pada usia 15 tahun keatas mencapai sekitar 6\% dari jumlah penduduk (Riskesdas Kemenkes, 2013).

Tujuan dalam pendidikan keperawatan adalah menghasilkan tenaga ahli keperawatan yang memiliki kemampuan intelektual, ketrampilan profesional, kesadaran sosial yang tinggi, serta berwawasan nasional dan global (Solikhah \& Elsanti, 2012) . Terciptanya perawat yang professional akan didukung oleh proses bimbingan klinik yang maksimal dalam hal ini penanganan pasien, proses anamnesa dan sebagainya, pemberian metode pembelajaran yang tepat, rumah sakit pendidikan yang memadai, serta perawat rumah sakit yang mengembangkan budaya komunitas professional keperawatan, akan menjadi fasilitas utama dalam penyelenggaraan pembelajaran klinik (Nursalam, 2009).

Mahasiswa mempersepsikan bahwa pembimbing klinik yang efektif dapat memperlakukan mahasiswa, klien, dan rekan kerjanya dengan penuh rasa hormat serta membimbing mahasiswa dalam mengelola permasalahannya (Valiee, dkk.
2016). Namun dalam penelitian pada mahasiswa jurusan keperawatan di Brigham Young University Provo Utha, bahwa mahasiswa sering diperhadapkan dengan situasi cemas, stress dan kondisi yang dinamis selama dalam pendidikan klinik (Locken \& Norberg, 2007). Salah satu faktor yang mempengaruhi terjadinya kecemasan pada mahasiswa pada saat melaksanakan praktek klinik keprawatan yaitu bimbingan yang diberikan CI atau pembimbing klinik yang ada (Rowbotham \& Owen, 2015)

Berdasarkan hasil studi pendahuluan oleh peneliti dengan metode wawancara pada mahasiswa semester 5 PSIK FK UNSRAT, tentang beberapa hal mengenai pengalaman saat melaksanakan praktek klinik keperawatan dalam proses bimbingan klinik, didapatkan bahwa dari 12 mahasiswa ada 9 mahasiswa yang menyatakan merasa cemas pada saat mendapatkan bimbingan yang kurang dikarenakan pembimbing klinik memiliki kesibukan dengan kegiatannya sebagai perawat sehingga jarang melakukan bimbingan kepada mahasiswa.

Fenomena yang terjadi di atas maka peneliti tertarik untuk melakukan penelitian tentang "Hubungan Persepsi Mengenai Proses Bimbingan Klinik dengan Tingkat Kecemasan pada Mahasiswa Praktek Klinik Keperawatan". Menurut peneliti penting untuk mengetahui apakah ada hubungan antara kedua variable ini karena dapat mengatahui sejauh mana proses bimbingan klinik yang mahasiswa dapatkan, yang dapat mengakibatkan adanya tingkat kecemasan sewaktu mengikuti praktek klinik keperawatan, sehingga untuk kedepannya proses bimbingan kinik akan lebih baik dan kecemasan pada mahasiswa berkurang.

\section{METODE PENELITIAN}

Penelitian ini merupakan penelitian kuantitatif dengan jenis non eksperimen (observasional), dengan menggunakan metode penelitian deskriptif analitik dengan 
pendekatan cross sectional. Penelitian ini dilakukan pada mahasiswa semester III PSIK FK Unsrat yang mengikuti praktek klinik di Rumah Sakit Bhayangkara dan Puskesmas Bahu Manado, dengan populasi sebanyak 73 orang. Pengambilan sampel pada penelitian ini menggunakan teknik pengambilan total sampling, yaitu mengambil ssampel dengan menggunakan keseluruhan anggota populasi untuk dijadikan sampel atau responden.

Penelitian ini menggunakan instrumen berupa kuesioner Zung SelfRating Anxiety Scale (ZSAS) untuk mengukur tingkat kecemasan pada mahasiswa yang terdiri dari 20 butir pernyataan dengan karakteristik kecemasan meliputi 5 pernyataan Favourable dan 15 pernyataan Unfavorable, dan kuesioner Nursing Clinical Teacher Effectiveness Inventory (NCTEI) untuk persepsi mengenai proses bimbingan klinik yang terdiri dari 51 butir pernyataan.

Jenis data yang digunakan pada penelitian ini adalah data primer dan data sekunder. Data primer adalah data yang diperoleh langsung dari responden dan data sekunder data yang diperoleh dari pihak kampus di Program Studi Ilmu Keperawatan Fakultas Kedokteran Unsrat. Pengolahan data yang diperoleh dari hasil penelitian ini diolah secara manual dengan mengelompokkan hasil dari lembar kuesioner yang dibagikan dan selanjutnya dilakukan analisis menggunakan uji statistik. Setelah itu diolah menggunakan sistem komputerisasi, tahap-tahap tersebut yaitu Editting, Coding, Proccessing, dan Cleaning. Analisis univariat dalam penelitian ini yaitu proses bimbingan klinik dan kecemasan pada mahasiswa praktek klinik keperawatan. Analisis bivariate dalam penelitian ini yaitu untuk melihat hubungan proses bimbingan klinik dengan kecemasan pada mahasiswa praktek klinik keperawatan dimana peneliti menggunakan uji Spearman Corelation.

\section{HASIL dan PEMBAHASAN}

Tabel 1. Distribusi Karakteristik Responden Berdasarkan Jenis Kelamin

\begin{tabular}{ccc}
\hline $\begin{array}{c}\text { Jenis Kelamin } \\
\text { Responden }\end{array}$ & $\mathbf{n}$ & $\mathbf{\%}$ \\
\hline Laki-laki & 7 & 9,6 \\
Perempuan & 66 & 90,4 \\
\hline Total & 73 & 100,0 \\
\hline
\end{tabular}

Sumber : Data Primer, 2018

Berdasarkan 73 responden menunjukkan bahwa responden terbanyak berjenis kelamin perempuan yaitu 66 orang $(90,4 \%)$, sedangkan responden laki-laki sebanyak 7 orang $(9,6 \%)$. Perempuan lebih rentan terkena gangguan mental mental emosional atau kecemasan karena disebabkan oleh adanya perubahan hormonal dan adanya perbedaan karakteristik antara laki-laki dan perempuan dan ketika menghadapi suatu permasalahan wanita lebih cenderung menggunakan perasaan (Iswanti, dkk. 2016).

Tabel 2. Distribusi Karakteristik Responden Berdasarkan Usia

\begin{tabular}{ccc}
\hline $\begin{array}{c}\text { Usia } \\
\text { Responden }\end{array}$ & $\mathbf{n}$ & $\mathbf{\%}$ \\
\hline 17 & 1 & 1,4 \\
18 & 32 & 43,8 \\
19 & 34 & 46,6 \\
20 & 5 & 6,8 \\
21 & 1 & 1,4 \\
\hline Total & 73 & 100,0
\end{tabular}

Sumber : Data Primer, 2018

Hasil penelitian dari 73 responden menunjukkan bahwa mayoritas responden dengan usia 19 tahun sebanyak 34 orang $(46,8 \%)$, dan yang berusia 18 tahun sebanyak 32 orang $(43,8 \%)$. Masa dewasa awal yang dilalui mahasiswa banyak hal baru yang ditemui didunia kampus, baik yang menyangkut masalah akademik seperti perkuliahan, maupun non akademik seperti bersosialisasi yang pada kondisi seperti ini, pola hidup yang tidak tepat akan membawa mahasiswa pada tingkat 
kejenuhan, kemalasan, kecemasan dan kebosanan dalam belajar (Widowati, 2017).

Tabel 3. Distribusi Karakteristik Responden Berdasarkan Persepsi Mengenai Proses Bimbingan Klinik

\begin{tabular}{ccc}
\hline Persepsi & & \\
Mengenai & & \\
Proses & $\mathbf{n}$ & \\
Bimbingan & & \\
Klinik & & 35,6 \\
\hline Baik & 26 & 64,4 \\
\hline Kurang Baik & 47 & 100,0 \\
\hline Total & 73 &
\end{tabular}

Sumber : Data Primer, 2018

Data yang diperoleh dari 73 responden didapati mayoritas responden memiliki persepsi yang kurang baik terkait proses bimbingan klinik sebanyak 47 orang $(64,4 \%)$. Proses bimbingan yang efektif dalam pendidikan klinik dibutuhkan untuk memfasilitasi dan mempersiapkan mahasiswa dengan baik dalam menentukan tujuan, metode, dan evaluasi pembelajaran sehingga mahasiswa dapat merasakan proses bimbingan yang baik dan dapa memotivasi mahasiswa dalam proses pembelajaran klinik. Karena setiap individu akan mempersepsikan suatu hal secara berbeda-beda sesuai dengan bagaimana sesorang melihat dan merasakan hal yang dia temui, seperti halnya dengan proses bimbingan yang ada antara mahasiswa praktek klinik dan pembimbing klinik itu sendiri (Syarifah, 2013).

Tabel 4. Distribusi Karakteristik Responden Berdasarkan Tingkat Kecemasan

\begin{tabular}{ccc}
\hline $\begin{array}{c}\text { Tingkat } \\
\text { Kecemasan }\end{array}$ & n & \% \\
\hline Cemas Ringan & 42 & 57,5 \\
Cemas Sedang & 27 & 37,0 \\
Cemas Berat & 4 & 5,5 \\
Panik & 0 & 0 \\
\hline Total & 73 & 100,0 \\
\hline
\end{tabular}

Sumber : Data Primer, 2018
Berdasarkan hasil penelitian dari 73 responden didapati mayoritas mahasiswa memliki tingkat kecemasan ringan yaitu sebanyak 47 responden $(57,5 \%)$. Faktorfaktor yang mempengaruhi kecemasan pada mahasiswa yaitu, latar belakang pendidikan, pengetahuan, lingkungan dan keterampilan (Asni , 2014). Kecemasan ringan merupakan ketegangan dalam kehidupan sehari-hari, yang membuat seseorang lebih waspada, perasaan raguragu dan hubungan dengan orang lain sangat dilibatkan dalam kecemasan yang terjadi (Donsu, 2017).

Tabel 5. Hubungan Persepsi Mengenai Proses Bimbingan Klinik dengan Tingkat Kecemasan pada Mahasiswa Praktek Klinik Keperawatan

\begin{tabular}{|c|c|c|c|c|c|c|c|c|}
\hline \multirow{3}{*}{ Kecemasan } & \multicolumn{6}{|c|}{$\begin{array}{c}\text { Persepsi Mengenai Proses } \\
\text { Bimbingan Klinik }\end{array}$} & \multirow{3}{*}{$r$} & \multirow{3}{*}{$\rho$} \\
\hline & \multicolumn{2}{|c|}{ Baik } & \multicolumn{2}{|c|}{ Kurang } & \multicolumn{2}{|c|}{ Total } & & \\
\hline & $\mathbf{n}$ & $\%$ & $\mathbf{n}$ & $\%$ & $\mathbf{n}$ & $\%$ & & \\
\hline $\begin{array}{l}\text { Cemas } \\
\text { Ringan }\end{array}$ & 26 & 35,6 & 16 & 21,9 & 42 & 57,5 & & \\
\hline $\begin{array}{l}\text { Cemas } \\
\text { Sedang }\end{array}$ & 0 & 0,0 & 27 & 37,0 & 27 & 37,0 & $-0,628$ & 0,000 \\
\hline $\begin{array}{l}\text { Cemas } \\
\text { Berat }\end{array}$ & 0 & 0,0 & 4 & 5,5 & 4 & 5,5 & & \\
\hline Panik & 0 & 0,0 & 0 & 0,0 & 0 & 0,0 & & \\
\hline Total & 26 & 35,6 & 47 & 64,4 & 73 & 100 & & \\
\hline
\end{tabular}

Sumber : Data Primer, 2018

Koefisien korelasi (r) antara hubungan persepsi mengenai proses bimbingan klinik keperawatan dengan tingkat kecemasan pada mahasiswa praktek klinik keperawatan semester III PSIK FK Unsrat di RS Bhayangkara dan Puskesmas Bahu Manado yaitu $r=-0,628$ (korelasi kuat bernilai negatif) yang berarti menunjukkan arah kedua variable mempunyai hubungan berlawanan, dengan kata lain jika mahasiswa mempersepsikan proses bimbingan klinik kurang baik maka tingkat kecemasan mahasiswa akan bertambah, dimana dalam hal ini mahasiswa masih merasakan kecemasan ringan. Dengan tingkat signifikan $\rho$ value $0,000<\alpha 0,05$ sehingga Ha diterima yaitu ada hubugan persepsi mengenai proses bimbingan klinik keperawatan dengan 
tingkat kecemasan pada mahasiswa praktek klinik keperawatan semester III PSIK FK Unsrat di RS Bhayangkara dan Puskesmas Bahu Manado.

Hasil penelitian ini sejalan dengan penelitian Sulistyowati (2009) yang berjudul persepsi mahasiswa tentang praktek klinik keperawatan dengan tingkat kecemasan pada mahasiswa S1 keperawtan UMS. Dengan hasil signifikan $(\rho) 0,001(<$ $0.05)$ yang berarti terdapat hubungan antara persepsi mahasiswa tentang praktek klinik keperawatan dengan tingkat kecemasan pada mahasiswa. Hal ini dibuktikan dengan hasil persepsi mahasiswa dalam kategori kurang baik dan tingkat kecemasan masuk dalam kategori kecemasan ringan.

Penelitian ini menunjukkan bahwa sebagian besar persepsi mahasiswa mengenai pembimbing klinik dalam kategori kurang baik, yang dibuktikan pada hasil kuesioner atau angket yang telah diisi oleh para mahasiswa, bahwa hubungan interpersonal yang dibangun pembimbing klinik serta kompetensi keperawatan yang dimiliki pembimbing klinik berada pada kategori agak buruk sampai pada kategori buruk, namun sebagaian besar mahasiswa hanya memiliki tingkat kecemasan ringan. Menurut Iswanti, dkk (2016) bahwa bila perasaan cemas menyerang seseorang, kemampuan berpikir, semangat dan kemauan belajarnya akan menurun. Hal tersebut juga akan berdampak negatif dalam peningkatan pengetahuan serta keterampilan mahasiswa. Selain itu faktor internal lainnya seperti pengetahuan, keterampilan, karakteristik kepribadian, pengalaman yang dimiliki mahasiswa juga turut andil dalam meningkatnya kecemasan pada mahasiswa (Khan, dkk. 2011).

Data yang diperoleh dari penelitian ini yaitu mahasiswa yang mempersepsikan proses bimbingan baik dengan tingkat kecemasan mahasiswa pada kategori ringan. Dari hasil angket yang dibagikan, beberapa mahasiswa berpresepsi bahwa proses evaluasi yang diberikan pembimbing klinik pada kategori baik dalam memberikan saran, mengamati kinerja mahasiswa, serta memberikan penguatan atau motivasi, Sehingga beberapa mahasiswa berada pada tingkat kecemasan ringan. Alifah (2017) mengemukakan, bahwa komunikasi serta hubungan yang baik dapat memberikan keuntungan bagi kedua belah pihak, dimana mahasiswa dapat menyampaikan masalah yang dimilikinya dan pembimbing klinik dapat mengerti dan membantu mahasiswa dalam proses pembelajaran, sehingga mahasiswa tidak merasa cemas.

Persepsi mahasiswa mengenai proses bimbingan klinik mempengaruhi tingkat kecemasan pada mahasiswa praktek klinik keperawatan, karena dari hasil kefisien korelasi yang didapatkan $(r=$ 0,628 ) bernilai negatife. Pembimbing klinik belum maksimal dalam memberikan bimbingan terhadap mahasiswa yang melaksanakan praktek klinik keperawatan, sehingga bebrapa mahasiswa mengalami cemas sedang sampai berat, namun mayoritas kecemasan mahasiswa berada pada kategori cemas ringan. Responden mengatakan kurang mendapatkan bimbingan dari pembimbing klinik, sehingga mahasiswa sulit mengaplikasikan teori yang mereka dapatkan saat perkuliahan dalam menangani pasien, serta masih ada rasa tidak percaya diri dan perasaan gugup pada saat melakukan tindakan keperawatan yang membuat mahasiswa merasa cemas. Hal ini menunjukkan bahwa lingkungan pembelajaran kurang baik dan sebagian besar pembimbing klinik melakukan proses bimbingan dengan kurang baik, namun tingkat kecemasan mahasiswa hanya berada pada kategori ringan. Hasil penelitian ini sejalan dengan penelitian oleh Saputra (2015) tentang hubungan lingkungan belajar klinik dengan tingkat kecemasan pada pembelajaran klinik mahasiswa keperawatan, yang mendapatkan hasil signifikan adanya hubungan antara kedua variable tersebut.

Faktor-faktor lain yang dapat mempengaruhi persepsi mahasiswa mengenai proses bimbingan klinik yaitu 
kesiapan mahasiswa untuk belajar dan prestasi mahasiswa. Dengan demikian peneliti menyimpulkan bahwa persepsi mahasiswa mengenai proses bimbingan klinik tidak selalu mempengaruhi tingkat kecemasan pada mahasiswa praktek klinik keperawatan. Para mahasiswa harus lebih percaya diri dan mengembangkan setiap skil yang ada dalam diri masing-masing dan lebih koperatif dalam menghadapi praktek klinik keperawatan, serta pembimbing klinik yang ada harus meningkatkan hubungan interpersonal dengan para mahasiswa serta mampu dalam mengevaluasi akan kinerja mahasiswa.

\section{SIMPULAN}

Berdasarkan hasil pembahasan mengenai hubungan persepsi mahasiswa mengenai proses bimbingan klinik dengan tingkat kecemasan pada mahasiswa praktek klinik keperawatan dapat disimpulkan bahwa :

1. Berdasarkan karakteristik mahasiswa yang diperoleh, sebagian besar usia mahasiswa berada pada golongan dewasa muda yaitu usia 18 dan 19 tahun, dengan mayoritas mahasiswa berjenis kelamin perempuan.

2. Sebagian besar mahasiswa mempersepsikan proses bimbingan klinik pada kategori kurang baik.

3. Mayoritas mahasiswa memiliki tingkat kecemasan yang ringan pada saat praktek klinik keperawatan.

4. Hasil uji statistik menunjukkan bahwa terdapat hubungan yang signifikan antara persepsi mahasiswa mengenai proses bimbingan klinik dengan tingkat kecemasan pada mahasiswa praktek klinik keperawatan.

\section{DAFTAR PUSTAKA}

Alifah, M., 2017. Hubungan Persepsi Mahasiswa Mengenai Pembimbing Klinik Terhadap Pencapaian Kompetensi Klinik Mahasiswa Keperawatan (Unpublished thesis). Departemen Ilmu Keperawatan Fakultas Kedokteran Universitas Diponegoro, Diponegoro
Asni, N. (2014). Faktor-Faktor Yang Memepengaruhi Kecemasan Mahasiswa Keperawatan Fikes UMP Menghadapi Praktek Klinik Keperawatan. Universitas Muhammadiyah Purwokerto, Purwokerto http://repository.ump.ac.id/5538/

Donsu Jenita. (2017). Psikologi Keperawatan. Jogjakarta: Pustaka Baru Press

Iswanti, D., Suratih K., \& Winasti W. (2016). Hubungan karakteristik dan lingkungan belajar klinik dengan kecemasan mahasiswa saat praktek klinik di rsjd dr amino gondohutomo semarang. STIKES Karya Husada Semarang. http://ppnijateng.org/wpcontent/uploads/2016/08/Keperawata n-Jiwa -place-PDF-vol-3-No-2rev.23-29.pdf (Diakses pada tanggal 23 September 2018, jam 21.43)

Khan BA, Ali F, Vazir N, Barolia R, Rehan S. Student's perceptions of clinical teaching and learning strategies : a Pakistani perspective. Nurse Educ Today. Available from: http://dx.doi.org/10.1016/j.nedt.2011. $\underline{01.016}$ (Diakses pada tanggal 18 Desember 2018, jam 22.23)

Locken, T. \& Norberg, H. (2007). Reduced anxiety improves learning ability of nursing students through utilization of mentoring triads. Collage of Nursing Utah. 1-5. Brigham Young University.

Nilawati, I., Sumarni, \& Santjaka A. (2013). Hubungan dukungan ibu dengan kecemasan remaja dalam menghadapi menarche di sd negeri lomanis 01 kecamatan cilacap tengah kabupaten cilacap .Akademi Kebidanan YLPP, Purwokerto http://www.akbidylpp.ac.id/ojs/index. php/Prada/article/view/76/67 (Diakses pada tanggal 23 September 2018, jam 23.13) 
Nursalam, (2009). Manajemen Keperawatan Aplikasi Dalam Praktik Keperawatan Profesional. Jakarta: Salemba Medika

Riskesdas. (2013). Riset Kesehatan Dasar. http://www.depkes.go.id/resources/do wnload/general/Hasil\%20Riskesdas\% 202013.pdf (Diakses pada tanggal 24 September 2018, jam 21.43)

Rowbotham, M., \& Owen, M. (2015). The effect of clinical nursing instructors on student self-efficacy. Nurse Educ Pract [Internet]. 2015;15(6):561-6. http://dx.doi.org/10.1016/j.nepr.2015. 09.008 (Diakses pada tanggal 24 Oktober 2018)

Saputra, O., \& Lisiswanti, R., (2015) Faktor-faktor yang mempengaruhi keberhasilan pembelajaran keterampilan klinik di Institusi Pendidikan Kedokteran. J Kedokt. 2015;5(9):104-9.

Seidi, P. (2017). Prevalence of social anxiety in students of college of education-university of garmian introduction. International Journal of Arts and Technology, 8(3), DOI: 10.18843/rwjasc/v8i3(1)/12

Solikhah, U. \& Elsanti, D. (2012). Pengaruh Bedside Teaching Model Terhadap Penguasaan Kasus Dan Kemampuan Ketrampilan Mahasiswa Praktik Klinik Keperawatan Fakultas Ilmu Kesehatan Universitas Muhammadiyah Purwokerto, 7(3), 142-147.

http://www.jks.fikes.unsoed.ac.id/ind ex.php/jks/article/view/401/228

(Diakses pada tanggal 23 September 2018, jam 22.40)

Sulistyowati, A. (2009). Hubungan persepsi mahasiswa tentang praktek klinik keperawatan dengan tingkat kecemasan pada mahasiswa s1 keperawatan ums. http://eprints.ums.ac.id/6414/1/J2100

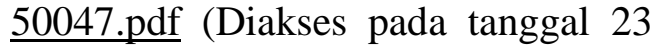
September 2018, jam 21.39)

Syarifah, S. (2013). Gambaran tingkat kecemasan mahasiswa keperawatan saat menghadapi ujian skil lab di universitas islam negeri syarif hidayatullah.

http://repository.uinjkt.ac.id/dspace/bi tstream/123456789/25674/1/SITI\%20 NURUS\%20SYARIFAH\%20\%20fkik.pdf (Diakses pada tanggal 23 September 2018, jam 22.53)

Valiee S, Moridi G, Khaledi S, Garibi F, (2016). Nursing students' perspectives on clinical instructors' effective teaching strategies: a descriptive study. Nurse Educ Pract [Internet]. 16(1):25862. Available from:http://dx.doi.org/10.1016/j.nepr.2 015.09.009

WHO. World Health Organization Mental Emotional Disorders Report: Globalhealth.gov; 2013 [cited 26 November 2016]. Available from:http://www.globalhealth.gov/glob al-health-topics/ mental emotional disorders report.html.

Widowati, S. (2017). Hubungan Tingkat Kecemasan Dengan Prestasi Belajar Pada Mahasiswa Program D3 Keperawatan. $\quad$ http://researchreport.umm.ac.id/index.php/researchreport/article/view/1400 (Diakses pada tanggal 18 Desember 2018, jam 21.05) 